\title{
Towards biomimetic red solar cells
}

\section{Lenau, Torben; Ahmad, Faiz; Lakhtakia, Akhlesh}

\section{Published in:}

Bioinspiration, Biomimetics, and Bioreplication IX

Link to article, DOI:

$10.1117 / 12.2513259$

Publication date:

2019

\section{Document Version}

Publisher's PDF, also known as Version of record

Link back to DTU Orbit

\section{Citation (APA):}

Lenau, T., Ahmad, F., \& Lakhtakia, A. (2019). Towards biomimetic red solar cells. In J. M-P. Raúl , M. Knez, \& A. Lakhtakia (Eds.), Bioinspiration, Biomimetics, and Bioreplication IX (Vol. 10965). [109650E] SPIE International Society for Optical Engineering. https://doi.org/10.1117/12.2513259

\section{General rights}

Copyright and moral rights for the publications made accessible in the public portal are retained by the authors and/or other copyright owners and it is a condition of accessing publications that users recognise and abide by the legal requirements associated with these rights.

- Users may download and print one copy of any publication from the public portal for the purpose of private study or research.

- You may not further distribute the material or use it for any profit-making activity or commercial gain

- You may freely distribute the URL identifying the publication in the public portal 


\section{Towards biomimetic red solar cells}

\section{Torben Lenau, Faiz Ahmad, Akhlesh Lakhtakia}

Torben Lenau, Faiz Ahmad, Akhlesh Lakhtakia, "Towards biomimetic red solar cells," Proc. SPIE 10965, Bioinspiration, Biomimetics, and Bioreplication IX, 109650E (13 March 2019); doi: 10.1117/12.2513259

SPIE Event: SPIE Smart Structures + Nondestructive Evaluation, 2019, Denver, Colorado, United States 


\title{
Towards biomimetic red solar cells
}

\author{
Torben Lenau ${ }^{* a}$, Faiz Ahmad ${ }^{b}$, and Akhlesh Lakhtakia ${ }^{\text {b, }}$ \\ ${ }^{a}$ Department of Mechanical Engineering, Technical University of Denmark, \\ DK-2800 Lyngby, Denmark \\ ${ }^{b}$ Department of Engineering Science and Mechanics, Pennsylvania State University, \\ University Park, PA 16802, USA \\ ${ }^{c}$ Material Architecture Center \& Department of Electronics Engineering, \\ Indian Institute of Technology (BHU), Varanasi 221005, India
}

\begin{abstract}
Silicon photovoltaic solar cells generally have a black or blue appearance that makes them aesthetically very different from traditional red roofs that either comprise burned-clay tiles or composite-material shingles. Rooftop solar cells may become more acceptable if they are similar in appearance to traditional roofs. This objective requires that the red part (620-700 nm wavelength) of the incoming solar spectrum be reflected so that it becomes unavailable for photovoltaic generation of electricity. Complete reflection of red photons would result in the reduction of useful solar photons (300$1200 \mathrm{~nm}$ wavelength) by $12.5 \%$. Calculations show that the optical short-circuit density will then decline by: $17 \%$ for $100-\mu \mathrm{m}$-thick crystalline-silicon solar cells, $20-22 \%$ for triple-junction tandem thin-film solar cells of amorphous silicon, $15-16 \%$ for $2.2-\mu \mathrm{m}$-thick CIGS solar cells, and 16-20\% for ultrathin CIGS solar cells. On average, the efficiency of a typical solar cell will have to be multiplied by a factor of 0.8 if all red photons were reflected. This reduction in efficiency can be offset by wider adoption of rooftop solar cells.

Red-rejection filters can be made of particulate composite materials containing, say, silica nanospheres. Typically, the solar cells will be iridescent then, which may not be aesthetically pleasing to many. Non-iridescent red-rejection filters can be fabricated by upscaling the linear dimensions of biomimetic filters nano-imprinted to reproduce the Morpho blue, this possibility being guaranteed by the scale invariance of the Maxwell equations and the weak dispersion of the refractive indexes of numerous polymers in the visible spectral regime. Non-uniformly red rooftop solar cells would also become feasible.
\end{abstract}

Keywords: Colored solar cells, biomimetics, rejection filter, structural colors, silicon solar cells, CIGS solar cells, tandem solar cells

*lenau@dtu.dk; phone +45 4525 4811; www.mek.dtu.dk

\section{INTRODUCTION}

Research focus on renewable sources of energy continues to intensify. There are several reasons for this intensification, the most important one is the climate-change threat that is manifesting significantly as the rise of annually and globally averaged temperatures and drastic reductions of polar ice levels. The rising temperatures are partly explained by the greenhouse effect caused by consumption of fossil fuels. Renewable energy from the sun, wind and water can replace fossil fuels but despite increased investment and lower prices, only $12 \%$ of the global energy consumption in 2017 was covered by renewable energy ${ }^{2}$. Panels of photovoltaic solar cells occupy valuable land that could otherwise be utilized for farming food and it is therefore relevant to consider alternative areas suited for placing the panels. The US National Renewable Energy Laboratory has estimated the potential extra electricity production to $300 \mathrm{GW}$ if all residential housing in the USA were covered by solar cells ${ }^{3}$. Roof tops are obvious places for the solar panels but there are several obstacles that prevent more widespread roof top installations.

One of the obstacles to rooftop installation of photovoltaic solar cells is the wish for visually aesthetic pleasing roof tops. Many house owners and tenants appreciate the aesthetic values of the appearance of their living and working places, and some of them resist the installation of solar panels on roof tops due to the change in appearance. Solar cells are typically

Bioinspiration, Biomimetics, and Bioreplication IX, edited by Raúl J. Martín-Palma, Mato Knez, Akhlesh Lakhtakia, Proc. of SPIE Vol. 10965, 109650E · @ 2019 SPIE · CCC code: 0277-786X/19/\$18 - doi: 10.1117/12.2513259 
bluish black and have macroscopically uniform flat surfaces, those features providing the maximum energy output. Roof claddings, such as red clay tiles, are often colored and have corrugated surfaces, in contrast.

The aesthetic requirements can be met by coloring solar cells with pigments. However, as pigments typically absorb part of the incoming light the energy efficiency will be reduced, thereby rendering the investment scenario less attractive. Besides, many pigments will degrade on daytime exposure to ultraviolet (UV) radiation. Structural colors ${ }^{4,5}$ are attractive alternatives to coloring since they can be made of UV-stable transparent materials which can allow a large fraction of the photons to pass through for conversion to electrical charges inside solar cells. In particular, it may be possible to make structural-color filters that selectively reflect a certain fraction of incident photons of certain colors in the visible part of the spectrum while transmitting almost all infrared photons.

Structural colors are normally iridescent, i.e., the perceived color changes depending on the viewing angle. A roof covered with structurally colored solar cells will therefore not have a uniform color, the hue depending on the viewing angle. In most cases, this will not be acceptable for house owners. However, the biological world has numerous examples of structural colors with varying degrees of iridescence incorporated on curved and even corrugated surfaces ${ }^{4,5}$. Investigation of appropriate biological examples leading to colored biomimetic surfaces could give valuable input on how to make colored solar cells.

\subsection{Red clay tiles}

To make solar cells more acceptable for rooftop installation, their appearance has to be closer to that of traditional roofs. Red clay tiles have been widely used all over the world for hundreds of years. Clay is an abundant and often locally available material and life times for roofs assembled from burned clay tiles can be very long - up to several hundred years. In addition to this durability which confers a positive historical image on red clay tiles, they are considered aesthetically pleasing. These issues pose a challenge for widespread use of bluish black solar cells on roof tops. If the visually attractive characteristics of red clay tiles could be transferred to solar cells, it is much more likely that they will be widely adopted in locales where red clay tiles are used.

It is not only a question of giving the solar cells the right red color. The visual characteristics also include the heterogeneous distribution of red hues as different tiles have slightly different red hues, and the color varies spatially on even a single tile. Another characteristic is the diffuse appearance of tiles so that the solar cells will need to reflect light in the same diffuse way. Thirdly, tiles are often curved, not flat, forming a corrugated roof surface.

\subsection{Empirical characterization of red clay tiles}

Reflection for red clay tiles was measured using a Shimadzu spectrometer with an integrating sphere. The tiles could be either dry or wet, as shown in Figure 1. As shown in Figure 2, whether dry or wet, a red tile reflects about $45 \%$ of the incident light in the red portion (620-700 nm wavelength) and $10 \%$ or less in the violet-to-green (380-560 nm wavelength) portion of the visible spectrum.
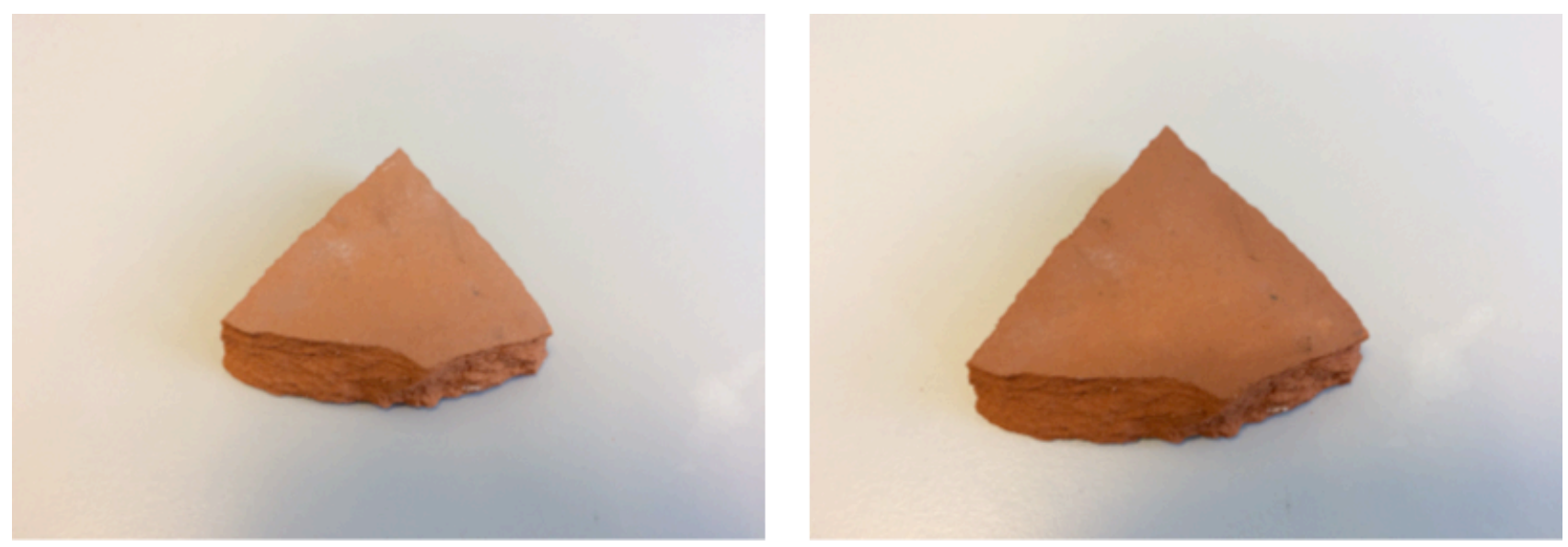

Figure 1. Dry (left) and wet (right) red clay tiles of transverse linear dimensions about $3.5 \mathrm{~cm}$. 


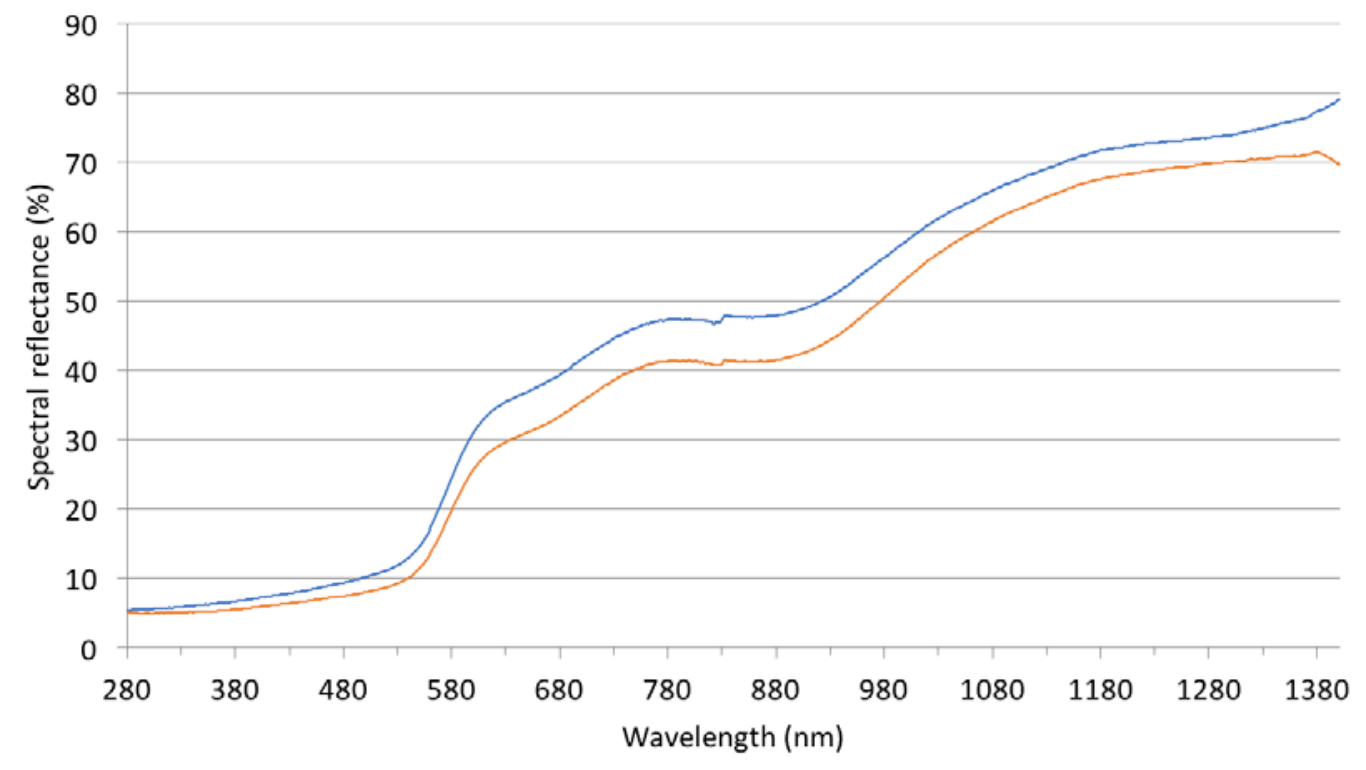

- Red 3 convex — Red 4 convex wetted

Figure 2. Spectral reflectance from dry and wet red clay tiles shown in Figure 1.

A solar cell can be characterized by its spectral response which is the ratio of current generated by it to the power incident on it. The spectral response is similar to the quantum efficiency, but there are differences in how measurements and calculations are made ${ }^{6}$. Figure 3 shows the measured spectral response ${ }^{7}$ of a silicon photovoltaic solar cell under glass. Calculated as the area under the curve, the total measured spectral response is about $45 \%$

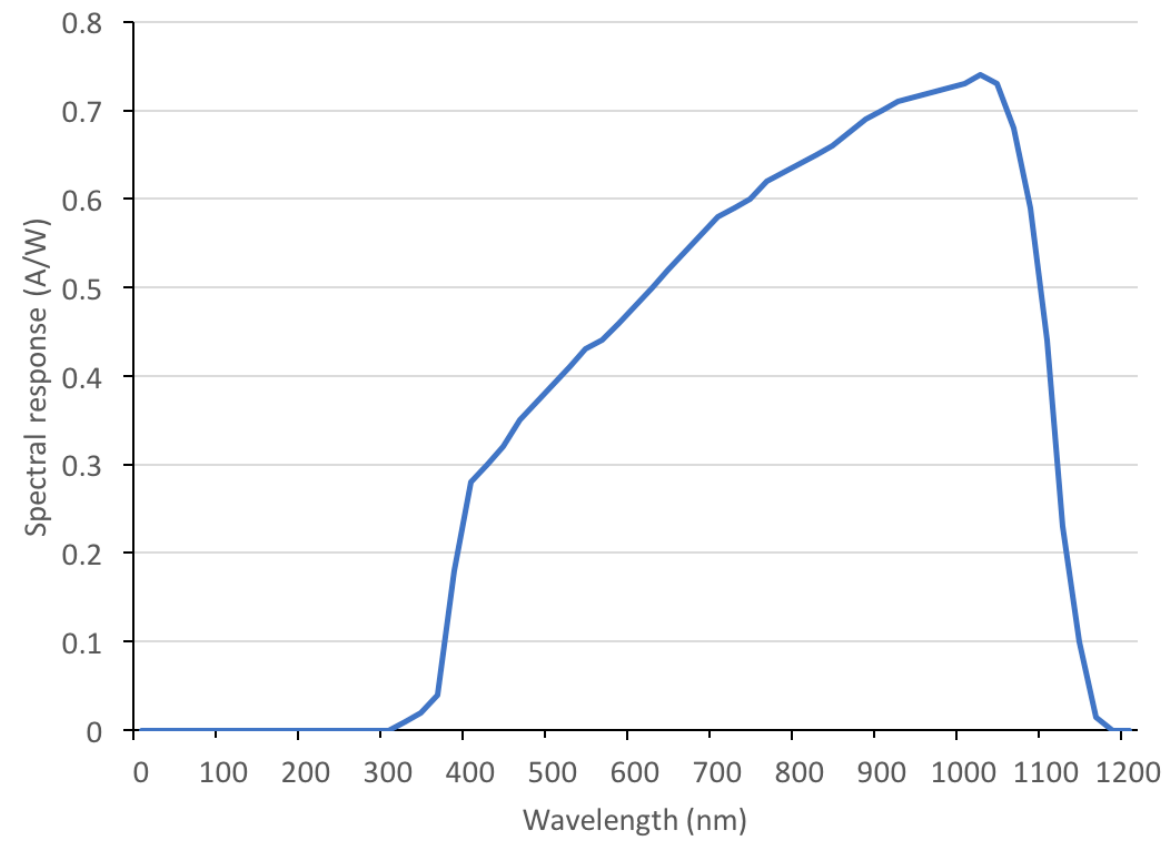

Figure 3. Measured spectral response (efficiency) of a silicon solar cell placed under glass. ${ }^{7}$

Figure 4 illustrates the effect of a filter that would reflect light in the same way as does the red clay tile, i.e., it reflects about $40 \%$ of the light in the red end of the spectrum and then gradually less down to about $10 \%$ for blue light. The 
remaining part of the light passes through the filter. Application of such a filter to the measured spectral response shown in Figure 3 will result in an efficiency drop from $45 \%$ to $39 \%$ (calculated as the area under the curve). Thus, the drop in efficiency is quite small.

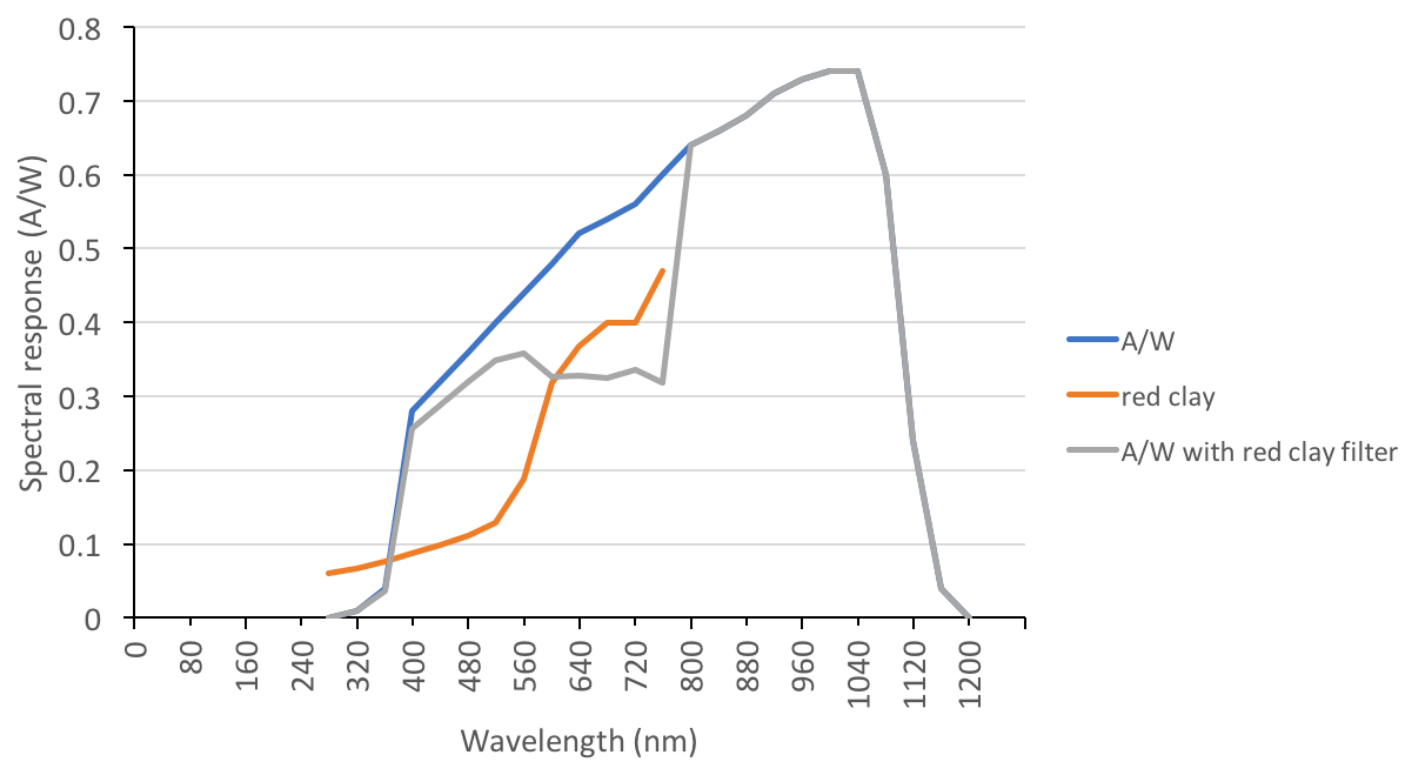

Figure 4. Grey curve: Spectral response of a photovoltaic silicon solar cell with red-rejection filter functioning similarly to a red tile. Blue curve: Spectral response of solar cell alone under glass (Fig. 3). Orange curve: Reflectance of a red tile alone.

\section{SOLAR CELL TECHNOLOGY \& COLOR}

\subsection{Solar cells and their efficiency}

Photovoltaic solar cells directly convert sunlight into electricity via the photoelectric effect. Tremendous progress has been made during the last decade, with rapid decrease in cost and rapid increase in installation capacity ${ }^{8,9}$. Whereas the theoretical upper limit for Si solar cells was calculated by Shockley and Queisser ${ }^{10}$ as $30 \%$, the dominant crystalline silicon (c-Si) technology is approaching $26.7 \%$ efficiency and multijunction solar cells have demonstrated an efficiency of $46 \%$, The cumulative installation capacity also increased hundredfold from $3 \mathrm{MW}$ to $300 \mathrm{MW}$ during the decade ending in $2017^{9}$.

Solar cells are categorized into three generations. The first-generation c-Si solar cells dominate the solar-cell industry with $95 \%$ share due to their high efficiency ${ }^{8,9}$, but they are costly because highly pure crystalline silicon is needed. The second-generation solar cells contain thin films of semiconductors. These solar cells are inexpensive because they require cheap materials and the processing techniques needed are also cheap. With 5\% market share, the dominant thinfilm solar cells are based on amorphous silicon (a-Si), cadmium telluride (CdTe), or copper indium gallium selenide (CIGS), with $11 \%, 21 \%$, and $22.9 \%$ efficiency, respectively ${ }^{9,12}$. The a-Si solar cells are used in tandem (multijunction configuration) due to their low efficiency. The third-generation solar cells are still in the experimental phase and include dye-sensitized, perovskite, nanostructured, concentrated, organic, nanocrystals, hybrid, and multijunction solar cells ${ }^{13}$.

The commonly used structure of a solar cells contains: antireflection coating(s), front electrode (which can also be a buffer layer), either a p-n or p-i-n junction, and a back electrode. Additional buffer layers may be present for a variety of reasons. We expect that the red-rejection filter (or any other colored filter) can be placed on top of antireflection coatings, as shown schematically in Figure 5.

With the aim of making completely black solar cells with very low reflectance, Davidsen et al. ${ }^{14-16}$ worked with black silicon including the bus-bars and thereby improved the aesthetic appearance. The aim is to make completely black solar cells with a very low reflectivity. They reported $18.1 \%$ efficiency ${ }^{16}$ for a nanostructured laser-doped selective emitter (LDSE) silicon solar cell with its surface textured with the single-step, mask-less, and scalable reactive-ion etching technique. 


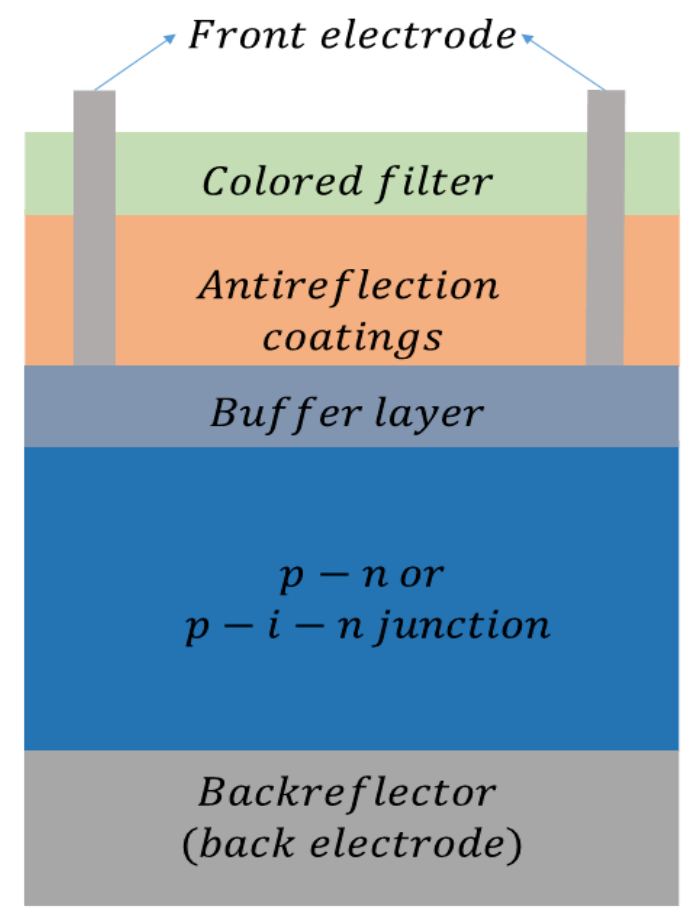

Figure 5. A simple solar cell with a colored filter.

The Amolf Institute in the Netherlands has produced a bright green solar cell ${ }^{17}$. The color ( $\sim 540$ nm wavelength) is of structural origin caused by scattering by a regular array of nanoscatterers printed on the top surface. The color can be observed from a wide range of viewing angles $\left(8-70^{\circ}\right)$. The effective power conversion efficiencies are ca. $18 \%$ compared to $20 \%$ for the unpatterned solar cell. This is equivalent to a relative reduction in efficiency of $10 \%$.

Kalkanoglu and colleagues have a patent describing a photovoltaic module that includes an encapsulated photovoltaic element and an infrared transmissive decorative overlay simulating conventional roofing ${ }^{18}$. The overlay is a coating of ink with nanoparticle ceramics. Tesla has a patent on camouflaging solar cells using louvers ${ }^{19}$. The louvers allow the sunlight to pass (which means it will look bluish-black when seen in the direction of the sun) while giving the roof the desired color when seen from below. Another patent from Akzo Nobel describe a solar cell where the parts of the cell not generating energy are covered by a colored layer coating ${ }^{20}$.

\section{SHORT-CIRCUIT CURRENT DENSITIES OF RED SOLAR CELLS}

Let us present data on the reduction of the optical short-circuit current density $J_{S c}^{O p t}$ predicted by a rigorous optical model for three different solar cells when red-rejection filters are employed to reflect normally incident red photons. Figure 6 shows schematics of all three solar cells: (a) a CIGS solar cell with a metallic one-dimensional periodically corrugated back reflector, (b) a tandem solar cell comprising three p-i-n junctions of a-Si with a metallic one-dimensional periodically corrugated back reflector, and (c) a single-junction c-Si solar cell with a metallic flat back reflector.

The rigorous coupled-wave approach ${ }^{21-23}$ was used to calculate $J_{s c}^{O p t}$ for normally incident unpolarized sunlight. The piecewise-uniform approximation was adopted to determine the optical electric and magnetic fields inside the solar cell, and thereafter the useful solar absorptance ${ }^{24}$ was calculated. With the assumption that every absorbed photon with energy greater than the bandgap excites an electron-hole pair, $J_{s c}^{O p t}$ was calculated taking the AM1.5G solar spectrum ${ }^{25}$ into account. Data on the relative-permittivity spectra of the materials used in all three solar cells in the optical spectral regime are available elsewhere ${ }^{24,26,27}$. Brief descriptions of the three solar cells follow. 


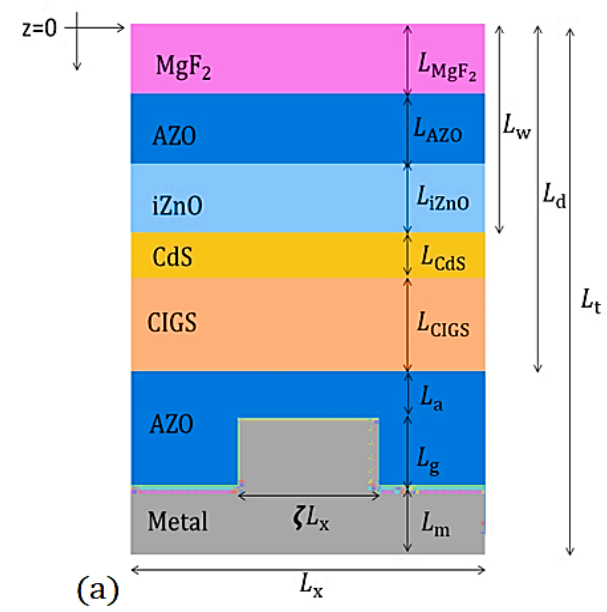

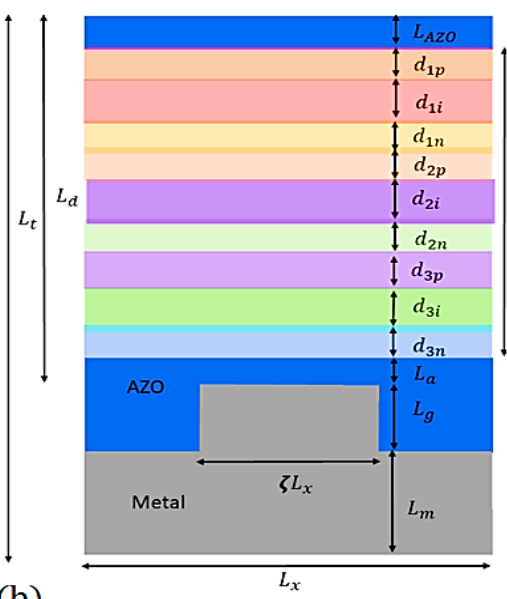

(b)

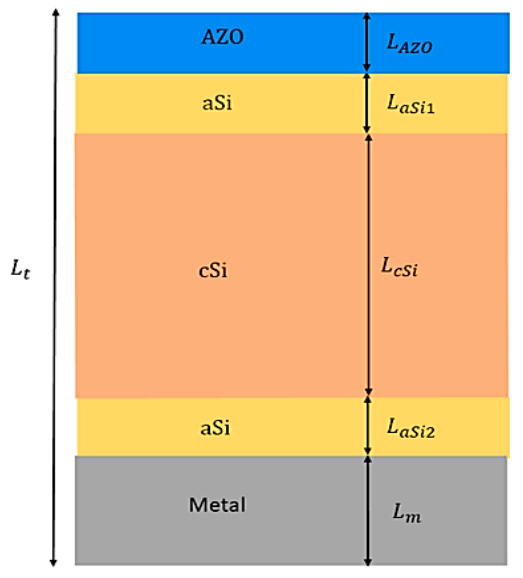

(c)

Figure 6. Schematics of (a) a CIGS solar cell with a metallic one-dimensional periodically corrugated back reflector, (b) a tandem solar cell comprising three $\mathrm{p}-\mathrm{i}-\mathrm{n}$ junctions of a-Si with a metallic one-dimensional periodically corrugated back reflector, and (c) single-junction c-Si solar cell with a metallic flat back reflector.

\subsection{CIGS solar cell}

The CIGS solar cell has the structure shown in Figure 6(a). The solar cell occupies the region

$$
X:\left\{(x, y, z) \mid-\infty<x<\infty,-\infty<y<\infty, 0<z<L_{t}\right\}
$$

with the half spaces $z<0$ and $z>L_{t}$ occupied by air. The reference unit cell of this structure is identified as

$$
\mathcal{R}:\left\{(x, y, z) \mid-\frac{L_{x}}{2}<x<\frac{L_{x}}{2},-\infty<y<\infty, 0<z<L_{t}\right\} .
$$

The window region $0<z<L_{w}=280 \mathrm{~nm}$ consists of a $110 \mathrm{~nm}$-thick $\mathrm{MgF}_{2}$ layer, a 100 -nm-thick AZO layer, and a 70$\mathrm{nm}$-thick layer of intrinsic zinc-oxide (iZnO). Together, the three layers function as an antireflection structure; the AZO layer also serves as an electrical contact as well. The region $L_{\mathrm{w}}<z<L_{\mathrm{w}}+L_{\mathrm{CdS}}$ is a 50 -nm-thick layer of n-type CdS that forms a junction with p-type CIGS layer of thickness $L_{\mathrm{CIGS}}=L_{\mathrm{d}}-L_{\mathrm{w}}=600 \mathrm{~nm}$. The region $L_{\mathrm{d}}<z<L_{\mathrm{d}}+L_{\mathrm{a}}$ is occupied by AZO to protect the electrical characteristics of the CIGS layer and it also functions as a passivation layer to reduce the back-surface electron-hole recombination rate. The 100-nm-thick region $L_{\mathrm{d}}+L_{\mathrm{a}}+L_{\mathrm{g}}<z<L_{\mathrm{t}}$ is occupied by silver the thickness being well beyond the penetration depth of silver in the solar-flux regime. The region $L_{\mathrm{d}}+L_{\mathrm{a}}<z<L_{\mathrm{d}}+L_{\mathrm{a}}$ $+L_{g}$ consists of a rectangular metallic grating with period $L_{x}$ along the $x$ axis and $\zeta \in[0,1]$ as the duty cycle.

The bandgap of the CIGS layer varies with $z$. As solar cells are fabricated using vapor-deposition techniques ${ }^{28}$, nonhomogeneous bandgap profiles could be physically realized by varying the relative proportions of gallium and indium during the deposition process ${ }^{29}$. Two profiles were selected for the bandgap. The sinusoidally nonhomogeneous bandgap was modeled as

$$
\mathrm{E}_{\mathrm{g}}(z)=\mathrm{E}_{\mathrm{g}, \text { min }}+A\left(1.626-\mathrm{E}_{\mathrm{g}, \min }\right)\left\{0.5\left[\sin \left(2 \pi \mathrm{K} \frac{z-L_{\mathrm{w}}}{L_{\mathrm{CIGS}}}-2 \pi \psi\right)+1\right]\right\}^{\alpha}, \quad z \in\left[L_{\mathrm{w}}, L_{\mathrm{d}}\right],
$$

where $\mathrm{E}_{\mathrm{g}, \min }$ is the minimum bandgap, $A$ is the amplitude (with $A=0$ representing a homogeneous CIGS layer), $\psi$ quantifies a relative phase shift, $K$ is the number of periods in the CIGS layer, and $\alpha>0$ is a shaping parameter. The linearly nonhomogeneous bandgap was modeled by

$$
\mathrm{E}_{\mathrm{g}}(z)=\mathrm{E}_{\mathrm{g}, \max }-A\left(\mathrm{E}_{\mathrm{g}, \max }-\mathrm{E}_{\mathrm{g}, \min }\right) \frac{z-L_{\mathrm{w}}}{L_{\mathrm{CIGS}}}, \quad z \in\left[L_{\mathrm{w}}, L_{\mathrm{d}}\right],
$$


where $A$ is the amplitude and $\mathrm{E}_{\mathrm{g}, \max }$ is the maximum bandgap. The parameters used for computations presented in this article for the sinusoidally nonhomogeneous CIGS bandgap are: $\mathrm{E}_{\mathrm{g} \text {,min }}=1.01 \mathrm{eV}, A=0.985, \alpha=6, \mathrm{~K}=4$, and $\psi=0.75$. The parameters used for computations presented in this article for the linearly nonhomogeneous CIGS bandgap are: $\mathrm{E}_{\mathrm{g}, \min }=1.08 \mathrm{eV}, \mathrm{E}_{\mathrm{g}, \max }=1.49 \mathrm{eV}$, and $A=0.75$. Both profiles are shown in Figure 7. Complete details of the formulation and the solution of the optical boundary-value problem are available elsewhere ${ }^{24}$.
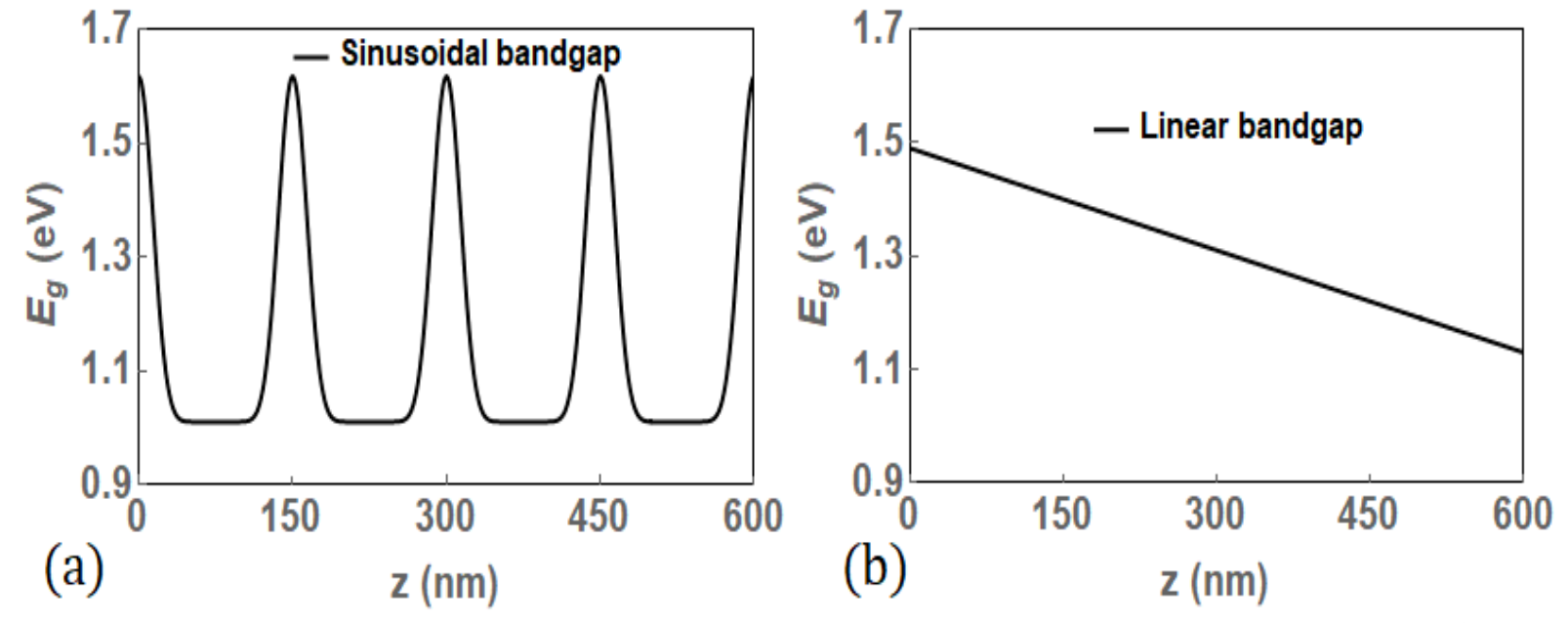

Figure 7 (a) Sinusoidally nonhomogeneous CIGS bandgap profile with $\mathrm{E}_{\mathrm{g}, \min }=1.01 \mathrm{eV}, A=0.985, \alpha=6, \mathrm{~K}=4$, and $\psi=0.75$. (b) Linearly nonhomogeneous CIGS bandgap profile with $\mathrm{E}_{\mathrm{g}, \min }=1.08 \mathrm{eV}, \mathrm{E}_{\mathrm{g}, \max }=1.49 \mathrm{eV}$, and $A=0.75$.

\subsection{Triple-junction tandem a-Si solar cell}

The triple-junction a-Si solar cell has the structure shown in Figure 6(b). Complete details of the formulation and the solution of the optical boundary-value problem are available elsewhere ${ }^{23,26}$. The solar cell occupies the region $X$ with the half spaces $z<0$ and $z>L_{t}$ occupied by air. The reference unit cell of this structure is identified as $\mathcal{R}$.

The regions $0<z<L_{\mathrm{AZO}}=110 \mathrm{~nm}$ and $L_{\mathrm{AZO}}+L_{\mathrm{s}}<z<L_{\mathrm{AZO}}+L_{\mathrm{s}}+L_{\mathrm{a}}$ with $L_{\mathrm{a}}=10$ are occupied by AZO. The region $L_{\mathrm{AZO}}<z<L_{\mathrm{AZO}}+L_{\mathrm{s}}$ is occupied by a cascade of homogeneous a-Si layers forming three p-i-n junctions. The 100-nmthick region $L_{\mathrm{d}}+L_{\mathrm{g}}<z<L_{\mathrm{t}}$ is occupied by silver. The region $L_{\mathrm{d}}<z<L_{\mathrm{d}+} L_{\mathrm{g}}$ consists of a rectangular metallic grating with period $L_{x}$ along the $x$ axis and $\zeta \in[0,1]$ as the duty cycle. The thicknesses of the a-Si layers and optical data are available elsewhere ${ }^{23,26}$. Complete details of the formulation and the solution of the optical boundary-value problem are also available elsewhere ${ }^{23,26}$.

\subsection{Single-junction c-Si solar cell}

The single-junction c-Si solar cell has the structure shown in Fig. 2(c). The solar cell comprises as 100-nm-thick AZO layer, a 10-nm-thick p-type a-Si layer, a 100- $\mu$ m-thick c-Si layer, a 10-nm-thick n-type a-Si layer, and a 100-nm-thick flat silver back reflector. Optical data are available elsewhere ${ }^{24,26,27}$. The formulation and the solution of the optical boundary-value problem are so simple as to be available from undergraduate textbooks ${ }^{30,31}$.

\subsection{Optical short-circuit current density}

First, we determined that red photons ( 620 and $700 \mathrm{~nm}$ wavelength) are $12.5 \%$ of useful solar photons (300 and $1200 \mathrm{~nm}$ wavelength). Next, the reduction in $J_{s c}^{O p t}$ resulting from the complete reflection of red photons was calculated for the three solar cells shown in Figure 6. Values of $J_{s c}^{o p t}$ for full-spectrum solar illumination and the red-deficient solar illumination are presented in Table I, along with the percentage decrease in $J_{s c}^{O p t}$ upon complete reflection of red photons. The relative decreases are: $14.4 \%$ for the $600-\mathrm{nm}$-ultrathin CIGS solar cell, $19.6 \%$ for the triple-junction a-Si solar cell, and $17 \%$ for the $100-\mu \mathrm{m}$-thick c-Si solar cell. Thus, the drops in efficiency are predicted to be small. 
Table I. $J_{S c}^{O p t}$ computed for full-spectrum and red-deficient solar illumination for the solar cells shown in Figure 6.

\begin{tabular}{|l|c|c|c|}
\hline Solar cell & $\begin{array}{c}\text { Full-spectrum } J_{s c}^{\text {Opt }} \\
\mathrm{mA} \mathrm{cm}\end{array}$ & $\begin{array}{c}\text { Red-deficient-spectrum } J_{s c}^{\text {Opt }} \\
\mathrm{mA} \mathrm{cm}\end{array}$ & $\begin{array}{c}\text { Relative decrease in } J_{s c}^{\text {Opt }} \\
\%\end{array}$ \\
\hline 600-nm-ultrathin CIGS & 36.13 & 30.91 & 14.4 \\
\hline Triple-junction a-Si & 23.97 & 19.25 & 19.6 \\
\hline Single junction c-Si & 34.21 & 28.39 & 17 \\
\hline
\end{tabular}

\section{OPTOELECTRONIC MODEL OF RED CIGS SOLAR CELL}

All photons are not equal because the energy of a photon depends on the free-space wavelength associated with it. Thus, the effect of the removal of red photons from solar illumination cannot be gauged from a purely optical model simply as a decrease in $J_{s c}^{O p t}$. Instead, a full optoelectronic model must be used to determine the effects on the short-circuit density $J_{S c}^{O p t}$, the open-circuit voltage $V_{o c}$, the efficiency $\eta$, and the fill factor $F F$. These parameters were calculated for normal incident unpolarized solar radiation using the rigorous-coupled wave approach for the photon absorption rate and therefore the electron-hole-pair generation rate and the drift-diffusion equations for electrical modeling of the CIGS-CdS (p-n) junction region $L_{w}<z<L_{d}{ }^{32,33}$. As the metallic back reflector is not in direct contact with the CIGS layer, it will not alter electron-hole transport in the p-n junction. A hybrid discontinuous Galerkin scheme ${ }^{34,35}$ was used for the driftdiffusion equations. Bandgap-varying electron affinity and defect density of states were incorporated in the model, as also were the Shockley-Read-Hall and radiative electron-hole recombination processes ${ }^{32}$. The electrical data of Frisk et $\mathrm{al}^{36}$. were used for calculations.

Let $f \in[0,1]$ denote the fraction of red photons that could have been absorbed but were reflected by the incorporation of a red reflector. Thus, $f=0$ represents maximum absorption of red photons and $f=1$ indicates no red photons were absorbed. We calculated $J_{S C}, V_{o c}, \eta$, and $F F$ for $f \in\{0,0.1,0.2, \ldots, 0.8,0.9,1.0\}$ for four different cases.

Table II. Short-circuit current density, open-circuit voltage, efficiency, and fill factor calculated for a 600-nm-thick CIGS solar cell with homogeneous bandgap $\left[\mathrm{E}_{\mathrm{g}, \min }=1.31 \mathrm{eV}\right.$ and $A=0$ in Eq. (3)] with a flat metallic backreflector [ $\left.\mathrm{Lg}=0\right]$.

\begin{tabular}{|c|c|c|c|c|c|}
\hline $\mathrm{f}$ & $\begin{array}{c}J_{S C} \\
\mathrm{~mA} \mathrm{~cm}^{-2}\end{array}$ & $\begin{array}{l}V_{o c} \\
\mathrm{mV}\end{array}$ & $\begin{array}{l}\eta \\
\%\end{array}$ & $\begin{array}{l}\mathrm{FF} \\
\%\end{array}$ & $\begin{array}{c}\text { Relative } \\
\text { decrease in } \eta \\
\%\end{array}$ \\
\hline 0 & 24.99 & 788 & 15.22 & 77 & \\
\hline 0.1 & 24.69 & 788 & 14.97 & 77.3 & 1.6 \\
\hline 0.2 & 24.22 & 787 & 14.77 & 77.4 & 2.9 \\
\hline 0.3 & 23.75 & 787 & 14.48 & 77.4 & 4.8 \\
\hline 0.4 & 23.28 & 786 & 14.18 & 77.4 & 6.8 \\
\hline 0.5 & 22.81 & 786 & 13.89 & 77.4 & 8.7 \\
\hline 0.6 & 22.34 & 785 & 13.59 & 77.4 & 10.7 \\
\hline 0.7 & 21.87 & 785 & 13.29 & 77.5 & 12.6 \\
\hline 0.8 & 21.40 & 784 & 13.00 & 77.5 & 14.5 \\
\hline 0.9 & 20.92 & 784 & 12.71 & 77.5 & 16.4 \\
\hline 1 & 20.45 & 783 & 12.41 & 77.5 & 18.4 \\
\hline
\end{tabular}


Table III. Short-circuit current density, open-circuit voltage, efficiency, and fill factor calculated for a 600-nm-thick CIGS solar cell with homogeneous bandgap $\left[\mathrm{E}_{\mathrm{g}, \min }=1.31 \mathrm{eV}\right.$ and $A=0$ in Eq. (3)] with a periodically corrugated metallic back reflector $\left[L_{x}=510 \mathrm{~nm}, \zeta=0.48\right.$, and $\left.L_{\mathrm{g}}=105 \mathrm{~nm}\right]$.

\begin{tabular}{|c|c|c|c|c|c|}
\hline $\mathrm{f}$ & $\begin{array}{c}J_{S C} \\
\mathrm{~mA} \mathrm{~cm}^{-2}\end{array}$ & $\begin{array}{l}V_{o c} \\
\mathrm{mV}\end{array}$ & $\begin{array}{l}\eta \\
\%\end{array}$ & $\begin{array}{l}\mathrm{FF} \\
\%\end{array}$ & $\begin{array}{c}\text { Relative decrease in } \eta \\
\%\end{array}$ \\
\hline 0 & 25.44 & 800 & 15.72 & 77.2 & \\
\hline 0.1 & 24.96 & 798 & 15.40 & 77.3 & 2.0 \\
\hline 0.2 & 24.49 & 797 & 15.11 & 77.3 & 3.8 \\
\hline 0.3 & 24.01 & 797 & 14.81 & 77.3 & 5.7 \\
\hline 0.4 & 23.54 & 796 & 14.51 & 77.4 & 7.6 \\
\hline 0.5 & 23.07 & 796 & 14.21 & 77.4 & 9.6 \\
\hline 0.6 & 22.59 & 795 & 13.91 & 77.4 & 11.5 \\
\hline 0.7 & 22.12 & 795 & 13.60 & 77.4 & 13.4 \\
\hline 0.8 & 21.64 & 794 & 13.31 & 77.4 & 15.3 \\
\hline 0.9 & 21.17 & 794 & 13.01 & 77.4 & 17.2 \\
\hline 1 & 20.70 & 793 & 12.71 & 77.4 & 19.1 \\
\hline
\end{tabular}

\subsection{Homogeneous bandgap and flat back reflector}

First, we considered the CIGS layer to have a homogeneous bandgap and the metallic back reflector to be flat. Values of $J_{s c}, V_{o c}, \eta$, and $F F$ are shown in Table II for $f \in\{0,0.1,0.2, \ldots, 0.8,0.9,1.0\}$. Also, the relative decrease in efficiency with respect to $f=0$ is provided in the same table. With the complete reflection of red photons, $\eta$ reduces to $12.41 \%$ from $15.22 \%$ for maximum absorption of red photons (relative decrease of $18.4 \%$ ) and $J_{s c}$ reduces to $20.45 \mathrm{~mA} \mathrm{~cm}{ }^{-2}$ from $24.99 \mathrm{~mA} \mathrm{~cm}^{-2}$ (relative decrease of $18.1 \%$ ), but the reduction in $V_{o c}$ is insignificant and $F F$ actually increases to $77.5 \%$ from $77 \%$. The efficiency is lowered to $13.89 \%$ from $15.22 \%$ (relative decrease of $8.7 \%$ ) as $f$ increases from 0 to 0.5 .

\subsection{Homogeneous bandgap and periodically corrugated back reflector}

Next, we considered the CIGS layer to have a homogeneous bandgap but the metallic backreflector to be periodically corrugated. Values of $J_{s c}, V_{o c}, \eta, F F$ and the relative decrease in $\eta$ with respect to $f=0$ are presented in Table III for $f \in\{0,0.1,0.2, \ldots, 0.8,0.9,1.0\}$. With the complete reflection of red photons, $\eta$ reduces to $12.71 \%$ from $15.72 \%$ for maximum absorption of red photons (relative decrease of $19.1 \%$ ) and $J_{s c}$ reduces to $20.70 \mathrm{~mA} \mathrm{~cm}$ from $25.44 \mathrm{mAcm}^{-2}$ (relative decrease of $18.6 \%$ ), but the changes in $V_{o c}$ and FF are insignificant. The efficiency is lowered to $14.21 \%$ from $15.72 \%$ (relative decrease of $9.6 \%$ ) as $f$ increases from 0 to 0.5 .

\subsection{Sinusoidally nonhomogeneous bandgap and periodically corrugated back reflector}

Next, we considered the CIGS layer to have a sinusoidally nonhomogeneous bandgap and the metallic backreflector to be periodically corrugated. Values of $J_{s c}, V_{o c}, \eta$, and $F F$ are shown in Table III for $f \in\{0,0.1,0.2, \ldots, 0.8,0.9,1.0\}$. Also, the relative decrease in efficiency with respect to $f=0$ is provided in the same table. With the complete reflection of red photons, $\eta$, reduces to $16.15 \%$ from $19.29 \%$ for maximum absorption of red photons (relative decrease of $16.2 \%$ ) and $J_{s c}$ reduces to $26.73 \mathrm{~mA} \mathrm{~cm}$ from $31.69 \mathrm{mAcm}^{-2}$ (relative decrease of $15.65 \%$ ), but the reduction in $V_{o c}$ is insignificant and $F F$ does not change at all. The efficiency is lowered to $17.69 \%$ from $19.29 \%$ (relative decrease of $8.2 \%)$ as $f$ increases from 0 to 0.5 . 
Table IV. Short-circuit current density, open-circuit voltage, efficiency, and fill factor calculated for a 600 -nm-thick CIGS solar cell with sinusoidally nonhomogeneous bandgap $\left[\mathrm{E}_{\mathrm{g}, \min }=1.01 \mathrm{eV}\right.$ and $A=0, \alpha=6, K=4$ and $\psi=0.75$ in Eq. (3)] with a periodically corrugated metallic back reflector $\left[L_{x}=510 \mathrm{~nm}, \zeta=0.48\right.$, and $L_{\mathrm{g}}=105 \mathrm{~nm}$ ].

\begin{tabular}{|c|c|c|c|c|c|}
\hline f & $\begin{array}{c}J_{S C} \\
\mathrm{~mA} \mathrm{~cm}{ }^{-2}\end{array}$ & $\begin{array}{l}V_{o c} \\
\mathrm{mV}\end{array}$ & $\begin{array}{l}\eta \\
\%\end{array}$ & $\begin{array}{l}\text { FF } \\
\%\end{array}$ & $\begin{array}{c}\text { Relative } \\
\text { decrease in } \eta \\
\%\end{array}$ \\
\hline 0 & 31.69 & 800 & 19.29 & 76 & \\
\hline 0.1 & 31.13 & 800 & 18.94 & 76 & 1.8 \\
\hline 0.2 & 30.64 & 799 & 18.64 & 76 & 3.3 \\
\hline 0.3 & 30.15 & 799 & 18.31 & 76 & 5.0 \\
\hline 0.4 & 29.66 & 798 & 18.01 & 76 & 6.6 \\
\hline 0.5 & 29.18 & 798 & 17.69 & 76 & 8.2 \\
\hline 0.6 & 28.69 & 797 & 17.39 & 76 & 9.8 \\
\hline 0.7 & 28.20 & 796 & 17.08 & 76 & 11.4 \\
\hline 0.8 & 27.71 & 796 & 16.77 & 76 & 13 \\
\hline 0.9 & 27.22 & 795 & 16.46 & 76 & 14.6 \\
\hline 1 & 26.73 & 795 & 16.15 & 76 & 16.2 \\
\hline
\end{tabular}

\subsection{Linearly nonhomogeneous bandgap and periodically corrugated back reflector}

Finally, we considered the CIGS layer to have a linearly nonhomogeneous bandgap and the metallic back reflector to be periodically corrugated. Values of $J_{s c}, \eta, F F$ and the relative decrease in $\eta$ with respect to $f=0$ are presented in Table $\mathrm{V}$ for $f \in\{0,0.1,0.2, \ldots, 0.8,0.9,1.0\}$. With the complete reflection of red photons, the efficiency reduces to $13.23 \%$ from $16.26 \%$ (relative decrease of $18.6 \%$ ). The efficiency is lowered to $14.80 \%$ from $19.29 \%$ (relative decrease of $8.9 \%)$ as $f$ increases from 0 to 0.5 .

On average, the optical model predicts that the efficiency of a CIGS solar cell will reduce by $17.6 \pm 1.4 \%$ if all red photons are reflected. The efficiency reduction will be $8.9 \pm 0.7 \%$ upon $50 \%$ reflection of red photons. These reductions are mainly due to reductions in the short-circuit current density, the open-circuit voltage and the fill factor being affected very little. Also, the relative decrease in efficiency is lower for higher-efficiency solar cells.

\section{OPTIONS FOR COLORATION}

\subsection{Pigments}

Extant colored photovoltaic solar cells use pigments ${ }^{37}$. Pigments absorb light in a specific portion of the visible spectrum but either reflect or transmit light in the remainder of the visible spectrum ${ }^{38}$. Absorption is caused by changes in energy levels in atoms and molecules, the absorbed energy being later released as infrared radiation. Pigments often absorb light in a fairly broad spectral band at varying intensities.

\subsection{Structural color}

In contrast to pigments, structural colors offer the opportunity of selective reflection in distinct spectral bands without significant absorption of light in the remainder of the visible spectrum. Structural colors are therefore well suited for achieving the exact reflection spectrum of red roof tiles while ensuring that photons of other colors are transmitted for charge-carrier generation in photovoltaic solar cells. Structural colors are used in many applications ${ }^{4,5}$ ranging from wall cladding on houses to decoration of glass frames and technical filters. 
Table V. Short-circuit current density, open-circuit voltage, efficiency, and fill factor calculated for a 600-nm-thick CIGS solar cell with linear nonhomogeneous bandgap $\left[\mathrm{E}_{\mathrm{g}, \min }=1.08 \mathrm{eV}, \mathrm{E}_{\mathrm{g}, \max }=1.49 \mathrm{eV}\right.$, and $A=0.75$ in Eq. (4)] with a periodically corrugated metallic back reflector $\left[L_{x}=510 \mathrm{~nm}, \zeta=0.48\right.$, and $\left.L_{\mathrm{g}}=105 \mathrm{~nm}\right]$.

\begin{tabular}{|c|c|c|c|c|c|}
\hline $\mathrm{f}$ & $\begin{array}{c}J_{S C} \\
\mathrm{~mA} \mathrm{~cm}\end{array}$ & $\begin{array}{l}V_{o c} \\
\mathrm{mV}\end{array}$ & $\begin{array}{l}\eta \\
\%\end{array}$ & $\begin{array}{l}\text { FF } \\
\%\end{array}$ & $\begin{array}{c}\text { Relative } \\
\text { decrease in } \eta \\
\%\end{array}$ \\
\hline 0 & 24.13 & 920 & 16.26 & 73.0 & \\
\hline 0.1 & 23.85 & 920 & 16.06 & 73.1 & 1.2 \\
\hline 0.2 & 23.39 & 919 & 15.74 & 73.1 & 3.2 \\
\hline 0.3 & 22.94 & 919 & 15.43 & 73.1 & 5.1 \\
\hline 0.4 & 22.48 & 918 & 15.12 & 73.1 & 7.0 \\
\hline 0.5 & 22.03 & 917 & 14.80 & 73.2 & 8.9 \\
\hline 0.6 & 21.57 & 917 & 14.48 & 73.2 & 10.9 \\
\hline 0.7 & 21.11 & 916 & 14.17 & 73.2 & 12.8 \\
\hline 0.8 & 20.66 & 916 & 13.86 & 73.2 & 14.7 \\
\hline 0.9 & 20.20 & 915 & 13.54 & 73.2 & 16.7 \\
\hline 1 & 19.75 & 914 & 13.23 & 73.2 & 18.6 \\
\hline
\end{tabular}

The structural-color effect can be achieved by relying on wavelength-dependent scattering of light by regular as well irregular structures. One option is to use periodically multilayered coatings where the refractive-index difference between adjacent layers causes interference to boost reflection in spectral bands that narrow as the number of periods is increased. The optical thicknesses of the layers need to be on the order of one-fourth of the desired wavelength. The coatings can be applied using physical vapor deposition or lamination of foils of polymer ${ }^{4,5,39}$. Another option is embossing nanostructures into the surface of a material using continuous printing techniques ${ }^{40}$. A third option could be to use particulate composite materials containing nanospheres of materials with a different refractive index. Embedding small particles or embossing imperfections in the surface layer can also be used to cause scattering of light of selected wavelengths.

Structural colors are iridescent, i.e., the color changes with the viewing angle. This is undesirable for rooftop application. However, iridescence can be avoided or reduced by properly engineering the physical structure responsible for the structural color. Saito et al. have nanoimprinted surfaces displaying the Morpho-blue color without iridescence ${ }^{41}$. Another example is furnished by multilayer polymer mirrors comprising alternating layers of the unirefringent poly(methyl methacrylate) and some birefringent polyester ${ }^{42}$. There is a shift in the reflected light depending on the incidence angle, but a very high broadband reflection is achieved within the visible regime.

\subsection{Bioinspired structural colors}

Many fish such as mackerel, herring and Salmon reflect light like a silver mirror, regardless of the angle of incidence. The reflectance is caused by a multilayer reflector in the fish scales with as few as five bilayers ${ }^{43,44}$. Each bilayer comprises a layer of cytoplasma (1.33 refractive index) and guanine (1.8 refractive index $)^{45,46}$, the huge refractive-index difference being responsible for broadband reflection ${ }^{39}$.

One of the most famous examples of structural colors in nature is the striking blue color of the wings of several different butterflies of the Morpho genus. The structural color is produced by alternating layers of chitin and air causing constructive interference within the short-wavelength portion of the visible spectrum ${ }^{47,48}$. Although interference colors are iridescent, the Morpho blue is independent of the viewing angle in a broad angular sector. The explanation is a combination of regular and irregular nanoscale structures that engender several wavelength-dependent phenomena ${ }^{47}$. The structural complexity of the Morpho wings is challenging to mimic, but Saito et al. ${ }^{41}$ and Chung et $\mathrm{al}^{49}$ have succeded in 
producing artificial counterparts. One solution is to use nanoimprinting based on laser fabrication and electroforming ${ }^{41}$. Another solution is the combination of a base layer of silica microspheres and a periodically multilayer structure ${ }^{49}$.

\section{CONTOURS OF A COLORED SOLAR CELL}

Non-uniformly red rooftop solar cells require a structural color that is independent of both the viewing angle and the direction of the incident light. Such a non-iridescent red-rejection filter could possibly be fabricated by upscaling the linear dimensions of biomimetic filters nanoimprinted to reproduce the morpho blue as described by Saito ${ }^{41}$. The scale invariance of the Maxwell equations ${ }^{50}$ and the weak dispersion of the refractive indexes in the visible spectral regime for many polymers together are in favor of such an upscaling ${ }^{51}$. Another option could be a combination of silica microspheres and a periodically multilayer structure as described by Chung ${ }^{49}$.

Apart from the color structure that will reflect a red color similar to the one from clay tiles, there are other factors affecting the aesthetic appearance. These features include the surface texture and the curvature of clay tiles as well as the mottled appearance of some types of clay tiles. The surface texture can be controlled through an outer coating with the right surface texture similarly to the way many beetles get their matte appearance. The curvature of the tiles is mainly a challenge for the base silicon wafer that needs to be so thin that it can be curved. The mottled appearance could be included in the generation of the structural color layers which need to be layout in a pattern so they reflect slightly different hues of red.

Another practical challenge is the size of the tiles. Traditional tiles are relatively small (typically $20 \mathrm{x} 40 \mathrm{~cm}$ ) which challenge how to connect the many tiles with the current-collecting circuit. One option could be to produce larger sections that from the outside appear to consist of several smaller tiles.

\section{CONCLUSION}

Solar cells represent an attractive renewable source of energy. However, they take up valuable land that otherwise could be used for other purposes such as farming. Roof tops are therefore promising interesting alternatives since they are not used for other purposes. In the US market alone, rooftop solar cells on all residential installations would be able to produce $300 \mathrm{GW}^{3}$. In this paper, we have argued that solar cells will be deployed on rooftops more extensively, provided that an aesthetic appearance closer to red-clay tile roof can be reached. Using empirical and mathematical models, we have analyzed the effect of coloring solar cells in a way that makes them similar to red clay tiles.

We have measured the reflection spectra of red clay tiles, finding that a filter reflecting light in the same way while allowing the non-red solar photons to pass will only cause a theoretical reduction of the spectral response from $45 \%$ to $39 \%$. However, this will only be the case in a theoretical ideal situation. Solar-cell modules are compound structures which are influenced by several factors affecting the amount of electricity produced. To investigate what can be achieved in practice we have calculated the expected optical short-circuit current density using a red-rejection filter $(620-700 \mathrm{~nm})$ for three different types of solar cells: (a) a CIGS solar cell with a metallic one-dimensional periodically corrugated back reflector, (b) a tandem solar cell comprising three p-i-n junctions of a-Si with a metallic onedimensional periodically corrugated back reflector, and (c) a single-junction c-Si solar cell with a metallic flat back reflector. An optical model predicts a reduction in the optical short-circuit current density between $14.4 \%$ and $19.6 \%$ for the three types of solar cells due to the use of the red-rejection filter. However, since all photons are not equal we have also made more comprehensive calculations using an optoelectrical model for the CIGS solar cell. On average, the efficiency of a CIGS solar cell will reduce by $17.6 \pm 1.4 \%$ if all red photons are reflected. The efficiency reduction will be $8.9 \pm 0.7 \%$ upon $50 \%$ reflection of red photons.

In order to realize red solar cells with an aesthetic appearance similar to red clay tiles with the highest efficiency, alternatives to existing pigment colors should be explored. We propose, with inspiration from biological structures to use structural color filters designed in a way so iridescence is avoided.

\section{ACKNOWLEDGEMENT}

A. Lakhtakia thanks the Charles Godfrey Binder Endowment at the Pennsylvania State University for ongoing support of his research. The research of F. Ahmad and A. Lakhtakia was partially supported by US National Science Foundation (NSF) under grant number DMS-1619901. 


\section{REFERENCES}

[1] Ripple, W. J., and 15, 371 scientists from 184 countries, "World scientists' warning to humanity: A second notice," Bioscience 67(12), 1026-1028 (2017).

[2] FS-UNEP Collaborating Centre for Climate \& Sustainable Energy Finance, "Global Trends in Renewable Energy Investment 2018," <https://europa.eu/capacity4dev/unep/documents/global-trends-renewable-energyinvestment-2018> (30 January 2019 ).

[3] Drury, E., Denholm, P., and Margolis, R., "Modeling the U.S. Rooftop Photovoltaics Market," Natl. Sol. Conf. 2010, 17-22 May 2010, Phoenix, USA(September) (2010).

[4] Lenau, T., "Nature inspired structural colour applications," [Biomimetic in Photonics], O. Karthaus, Ed., CRC Press / Taylor Francis, 72-96 (2012).

[5] Dushkina, N., and Lakhtakia, A., "Structural Colors," [Engineered Biomimicry], R. J. Lakhtakia, A., and MartínPalma, Ed., Elsevier, Waltham, MA, USA , 267-303 (2013).

[6] Hartman, J. S., and Lind, M. A., "Spectral response measurements for solar cells," Sol. Cells 7(1-2), 147-157 (1982).

[7] Honsberg, C., and Bowden, S., "Spectral Response," PVEducation.org, 2018, $<$ https://www.pveducation.org/pvcdrom/spectral-response $>$ (11 November 2018 ).

[8] International Energy Agency, "World Energy Outlook 2017," <https://www.iea.org/weo2017/> (22 November 2018 ).

[9] Fraunhofer Institute for Solar Energy Systems ISE, "Photovoltaics Report, Technical Report," 2018, $<$ https://www.ise.fraunhofer.de/en.html $>$ (30 January 2019 ).

[10] Shockley, W., and Queisser, H. J., "Detailed balance limit of efficiency of p-n junction solar cells," J. Appl. Phys. 32(3), 510-519 (1961).

[11] Green, M. A., Hishikawa, Y., Dunlop, E. D., Levi, D. H., Hohl-Ebinger, J., and Ho-Baillie, A. W. Y., "Solar cell efficiency tables (version 51)," Prog. Photovoltaics Res. Appl. 26, 3-12 (2018).

[12] National Renewable Energy Laboratory, "Champion Module Efficiencies," 2018, $<$ https://www.nrel.gov/pv/assets/pdfs/research-module-efficiency-chart.20190128.pdf> (30 January 2019 ).

[13] Singh, R., Alapatt, G. F., and Lakhtakia, A., "Making Solar Cells a Reality in Every Home: Opportunities and Challenges for Photovoltaic Device Design," IEEE J. Electron Devices Soc. 1(6), 129-144 (2013).

[14] Davidsen, R. S., Tang, P. T., Mizushima, I., Thorsteinsson, S., Poulsen, P. B., Frausig, J., Nordseth, Ø., and Hansen, O., "Black silicon solar cells with black ribbons," Proc. Eur. Photovolt. Sol. Energy Conf., 20-24 June 2016, Munich, Ger., 631-634 (2016).

[15] Davidsen, R. S., [Nanostructuring of Solar Cell Surfaces], Technical University of Denmark (2016).

[16] Davidsen, R. S., Li, H., To, A., Wang, X., Han, A., An, J., Colwell, J., Chan, C., Wenham, A., Schmidt, M. S., Boisen, A., Hansen, O., Wenham, S., and Barnett, A., "Black silicon laser-doped selective emitter solar cell with 18.1\% efficiency," Sol. Energy Mater. Sol. Cells 144(1), 740-747 (2016).

[17] Neder, V., Luxembourg, S. L., and Polman, A., "Efficient colored silicon solar modules using integrated resonant dielectric nanoscatterers," Appl. Phys. Lett. 111(7) (2017).

[18] Kalkanoglu, H. M., Jacobs, G. F., and Shiao, M. L., "Photovoltaic module," US 2008/0006323 A1 (2008).

[19] Pilliod, M., Gougoussis, C., Lefevre, O., Laurin, M., and Liu, J., "Obscuring, color matching, and camouflaging solar panels," US2018/0122973A1, 43 (2018).

[20] Jongerden, G. J., Middelman, E., Andel, E. van, Schropp, R. E. I., Peters, P. M. G. M., and Hesselink, D. E., "Colored solar cell unit," US7227078B2 (2007).

[21] Glytsis, E. N., and Gaylord, T. K., "Rigorous three-dimensional coupled-wave diffraction analysis of single and cascaded anisotropic gratings," J. Opt. Soc. Am. A 4(11), 2061 (1987).

[22] Polo, J., Mackay, T., and Lakhtakia, A., [Electromagnetic Surface Waves: A Modern Perspective], Elsevier,Waltham, MA, USA (2013).

[23] Ahmad, F., Anderson, T. H., Civiletti, B. J., Monk, P. B., and Lakhtakia, A., "On optical-absorption peaks in a nonhomogeneous thin-film solar cell with a two-dimensional periodically corrugated metallic backreflector," J. Nanophotonics 12(1), 16017 (2018).

[24] Ahmad, F., Anderson, T. H., Monk, P. B., and Lakhtakia, A., "Optimization of light trapping in ultrathin nonhomogeneous CuIn $1-\xi \mathrm{Ga} \xi \mathrm{Se} 2$ solar cell backed by $1 \mathrm{D}$ periodically corrugated backreflector," Proc. SPIE 10731(1), 107310L (2018).

[25] National Renewable Energy Laboratory, "Reference Air Mass 1.5 Spectra | Grid Modernization | NREL," 
$<$ https://www.nrel.gov/grid/solar-resource/spectra-am1.5.html> (1 February 2019 ).

[26] Ahmad, F., Anderson, T. H., Civiletti, B. J., Monk, P. B., and Lakhtakia, A., "On optical-absorption peaks in a nonhomogeneous dielectric material over a two-dimensional metallic surface-relief grating," Proc. SPIE 10356(1), 103560I (2017).

[27] Green, M. A., "Self-consistent optical parameters of intrinsic silicon at $300 \mathrm{~K}$ including temperature coefficients," Sol. Energy Mater. Sol. Cells 92(11), 1305-1310 (2008).

[28] Martín-Palma, R. J., and Lakhtakia, A., [Nanotechnology: A Crash Course] (2010).

[29] Anderson, T. H., Mackay, T. G., and Lakhtakia, A., "Enhanced efficiency of Schottky-barrier solar cell with periodically nonhomogeneous indium gallium nitride layer," J. Photonics Energy 7(1), 14502 (2017).

[30] Iskander, M. F., [Electromagnetic Fields and Waves], Waveland Press, Long Grove, IL, USA (2012).

[31] Balanis, C. A., [Advanced Engineering Electromagnetics], Wiley, Hoboken, NJ, USA (2012).

[32] Fonash, S. J., [Solar Cell Device Physics], Academic Press, Burlington, MA, USA (2010).

[33] Nelson, J., [The Physics of Solar Cells], Imperial College Press, London, UK (2003).

[34] Fu, G., Qiu, W., and Zhang, W., "An analysis of HDG methods for convection-dominated diffusion problems," ESAIM Math. Model. Numer. Anal. 49(1), 225-256 (2015).

[35] Chen, Y., Kivisaari, P., Pistol, M.-E., and Anttu, N., "Optimization of the short-circuit current in an InP nanowire array solar cell through opto-electronic modeling," Nanotechnology 27(43), 435404 (2016).

[36] Frisk, C., Platzer-Björkman, C., Olsson, J., Szaniawski, P., Wätjen, J. T., Fjällström, V., Salomé, P., and Edoff, M., "Optimizing Ga-profiles for highly efficient $\mathrm{Cu}(\mathrm{In}, \mathrm{Ga}) \mathrm{Se} 2$ thin film solar cells in simple and complex defect models," J. Phys. D. Appl. Phys. 47(48), 485104 (2014).

[37] Krydsrum Arkitekter, "Røde solceller - BASE - Krydsrum Arkitekter,” 2015, $<\mathrm{http}: / / \mathrm{kryds}$ srum.dk/projekter/base/> (22 January 2019 ).

[38] Tilley, R. J. D., [Colour and the Optical Properties of Materials], John Wiley \& Sons, Ltd, Chichester, UK (2010).

[39] Baumeister, P., [Optical coating technology], SPIE Optical Engineering Press (2004).

[40] Kristensen, A., Yang, J. K. W., Bozhevolnyi, S. I., Link, S., Nordlander, P., Halas, N. J., and Mortensen, N. A., "Plasmonic colour generation," Nat. Rev. Mater. 2, 16088 (2016).

[41] Saito, A., Murase, J., Yonezawa, M., Watanabe, H., Shibuya, T., Sasaki, M., Ninomiya, T., Noguchi, S., Akaikasaya, M., and Kuwahara, Y., "High-throghput reproduction of the Morpho butterfly's specific high contrast blue," Proc. SPIE 8339(1), 83390C (2012).

[42] Weber, M. F., Stover, C. A., Gilbert, L. R., Nevitt, T. J., and Ouderkirk, A. J., "Giant Birefringent Optics in Multilayer Polymer Mirrors," Science (80-. ). 287(5462), 2451-2456 (2000).

[43] Denton, E. J., and Land, M. F., "Mechanism of Reflexion in Silvery Layers of Fish and Cephalopods," Proc. R. Soc. Lond. B 178(1050), 43-61 (1971).

[44] Denton, E., "Reflectors in Fishes," Sci. Am. 224(1), 64-72 (1971).

[45] Fujii, R., "Coloration and chromatophores," [The Physiology of Fish], D. H. Evans, Ed., CRC Press, 535 - 562 (1993).

[46] Vukusic, P., "Natural Coatings," [Optical Interference Coatings], N. Kaiser and H. K. Pulker, Eds., Springer, New York, 1-34 (2003).

[47] Kinoshita, S., Yoshioka, S., and Kawagoe, K., "Mechanisms of structural colour in the Morpho butterfly: cooperation of regularity and irregularity in an iridescent scale," Proc. R. Soc. London. Ser. B Biol. Sci. 269(1499), 1417-1421 (2002).

[48] Vukusic, P., and Sambles, J. R., "Photonic structures in biology," Nature 424(6950), 852-855 (2003).

[49] Chung, K., Yu, S., Heo, C. J., Shim, J. W., Yang, S. M., Han, M. G., Lee, H. S., Jin, Y., Lee, S. Y., Park, N., and Shin, J. H., "Flexible, angle-independent, structural color reflectors inspired by morpho butterfly wings," Adv. Mater. 24(18), 2375-2379 (2012).

[50] Sinclair, G., "Theory of models of electromagnetic systems," Proc. I.R.E 36(11), 1364-1370 (1948).

[51] Vepachedu, V., and Lakhtakia, A., "Chiral sculptured thin films for circular polarization of mid-wavelength infrared light,” Appl. Opt. 57(22), 6410-6416 (2018). 